\title{
THE INFLUENCE OF EARLY LEFT VENTRICLE REMODELING OVER QTC CHANGES IN HIGHLY TRAINED PREADOLESCENT FOOTBALLERS
}

Marija Zdravkovic ${ }^{1}$, Branişav Milovanovic ${ }^{1}$, Mirjana Krotin ${ }^{1}$, Sinisa Dimnkovic ${ }^{1}$, Dragan Lovic $^{2}$, Branka Filipovic ${ }^{1}$, Olivera Markovic ${ }^{1}$, Darko Zdravkovic $^{1}$, Sergej Prijic ${ }^{3}$, Vladimir Vukomanovic ${ }^{3}$, Goran Koracevic ${ }^{4}$, Ivan Soldatovic ${ }^{5}$, Tijana Acimovic ${ }^{6}$, Ivana Dizdarevic ${ }^{7}$, Sanja Mazic $^{2}$

Aim. To assess the correlation between left ventricle remodeling induced by physical training with QTc duration in preadolescent professional football players.

Material and methods. Ninety-four highly trained male footballers (mean aged $12,85 \pm 0,84$ ) competing in the Serbian Football League (at least 7 training hours/ week) and 47 age-matched healthy male controls were enrolled in the study. Main outcome measures: They were screened by ECG and echocardiography at a tertiary referral cardio center. The control group had sedentary life style (less than 2 training hours/week). QTc values and left ventricle dimensions were compared in these two groups.

Results. In all participants, normal values of QTc interval were registered. Mean QTC in athletes was significantly higher compared to non-athletes $(419,89 \pm 13,07 \mathrm{msec}$ vs $399,78 \pm 13,27 \mathrm{msec})(p<0,001)$. QTc interval had strong positive correlation to left atrium dilatation, LV dilatation, LV mass and LV mass index. There was no correlation between QTc interval and LV wall thickness, but there were correlations between QTC interval duration and specific LV mass indexes (LVM/BSA ${ }^{1,5}$ and LVM/ ${ }^{2.7}$ ).

Conclusion. QTC interval prolongation is present in early stage of athlete's heart remodeling, hence QTc prolongation could be the early ECG marker of physiological LV remodeling in young preadolescent footballers, without any other standard ECG and echocardiographic signs of early LV hypertrophy. This could be explained by a different pattern of left ventricle remodeling in preadolescent period, where LV wall thickness increase cannot usually be seen and the predominant characteristic is left ventricle dilatation.

Russ J Cardiol 2014, 7 (111), Engl.: 23-27

Key words: athletes, cardiology, echocardiography, electrocardiography, heart, footballers.
'University Hospital Medical Center Bezanijska Kosa, Faculty of Medicine, University of Belgrade, Belgrade; ${ }^{2}$ Clinic for Internal Medicine Intermedica, Nis; ${ }^{3}$ Institute for Child and Mother Care "Vukan Cupic", Dept. of Cardiology, Faculty of Medicine, University of Belgrade, Belgrade; ${ }^{4}$ Clinic for Cardiology, Faculty of Medicine, University of Nis, Nis; ${ }^{5}$ Institute for Medical Statistics, Faculty of Medicine, University of Belgrade, Belgrade; ${ }^{6}$ Institute for Physiology, Faculty of Medicine, University of Belgrade, Belgrade; ${ }^{7}$ Clinical Center of Serbia, Faculty of Medicine, University of Belgrade, Belgrade, Serbia.

Corresponding author. Marija Zdravkovic, Dr, Assistant Professor, MD, PhD, FESC. University Hospital Medical Center Bezanijska Kosa, Faculty of Medicine, University of Belgrade, Belgrade, Serbia. Tel: +381652270301, Fax: +381112606520, e-mail: sekcija.kardioloska@gmail.com

QTC- QT corrected, LV - left ventricle, BSA- body surface area, ECG electrocardiogram, LA - left atrium, AO - aortic root (AO), LVED - left ventricular end diastolic dimension, LVES - left ventricle end systolic dimension, PWd - left ventricle posterior wall diastolic dimension, IVSd - interventricular septal diastolic dimension, ASE - American Society of Echocardiography, LVM - left ventricular mass, LQTS - long QT syndrome, SD — standard deviation, h — height, LVH - left ventricular hypertrophy, QRS d - QRS duration, QRS v - QRS voltage, PR interval - duration of $\mathrm{PR}$ interval, $\mathrm{P}$ wave $\mathrm{v}-\mathrm{P}$ wave voltage, $\mathrm{HR}$ - heart rate.

Received March 19, 2014

Revision received April 11, 2014

Accepted April 18, 2014

\section{ВЛИЯНИЕ РАННЕГО РЕМОДЕЛИРОВАНИЯ ЛЕВОГО ЖЕЛУДОЧКА ПРИ ИЗМЕНЕНИЯХ QТС У ВЫСОКОКВАЛИФИЦИРОВАННЫХ НЕПОЛОВОЗРЕЛЫХ ФУТБОЛИСТОВ}

Marija Zdravkovic ${ }^{1}$, Branișlav Milovanovic ${ }^{1}$, Mirjana Krotin ${ }^{1}$, Sinisa Dimnkovic ${ }^{1}$, Dragan Lovic $^{2}$, Branka Filipovic ${ }^{1}$, Olivera Markovic ${ }^{1}$, Darko Zdravkovic ${ }^{1}$, Sergej Prijic ${ }^{3}$, Vladimir Vukomanovic ${ }^{3}$, Goran Koracevic ${ }^{4}$, Ivan Soldatovic ${ }^{5}$, Tijana Acimovic ${ }^{6}$, Ivana Dizdarevic ${ }^{7}$, Sanja Mazic $^{2}$

Цель. Для оценки корреляции между ремоделированием левого желудочка, индуцированной физическими нагрузками, и продолжительностью QTс у неполовозрелых профессиональных футболистов.

Материал и методы. Девяносто четыре высококвалифицированных футбо-

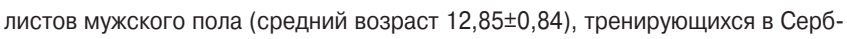
ской Футбольной Лиге (по крайней мере, 7 учебных часов в неделю) и 47 повозрасту здоровых мужчин были включены в исследование. Основные критерии оценки: они были обследованы с помощью ЭКГ и ЭхоКГ в местном кардиологическом центре. Исследуемые в контрольной группе вели малоподвижный образ жизни (менее 2 учебных часа в неделю). Значения QTс и размеры левого желудочка сравнивались у этих двух групп.

Результаты. Нормальные значения интервала QTс были зарегистрированы у всех участников. Значения QTс у спортсменов были значительно выше, по сравнению с не-спортсменами $(419,89 \pm 13,07$ мc vs $399,78 \pm 13,27$ мс) ( $p<0,001)$. Интервал QTс имел сильную положительную корреляцию к дилатации левого предсердия, дилатации ЛЖ, ЛЖ массы и индексу массы ЛЖ. Не было никакой корреляции между интервалом QТс и толщиной стенки ЛЖ, но имелась корреляция между интервалом QTс, длительностью и специфичностью индекса массы ЛЖ (LVM/BSA ${ }^{1,5}$ and LVM $/ \mathrm{h}^{2.7}$ ).

Заключение. Удлинение интервала QTс присутствует в ранней стадии ремоделирование сердца спортсмена и, следовательно, удлинение QTC может быть ранним ЭКГ-маркером физиологического ремоделирования лж у молодых неполовозрелых футболистов, без каких-либо других стандартных ЭКГ и эхокардиографических признаков ранней гипертрофии Лж. Это может быть объяснено различной формой ремоделирования ЛЖ в половозрелый период, когда увеличение толщины стенки Лж невозможно определить визуально и предоминантная характеристика является увеличением Лж

Российский кардиологический журнал 2014, 7 (111), Англ.: 23-27

Ключевые слова: спортсмены, кардиология, эхокардиография, электрокардиография, сердце, футболисты.

${ }^{1}$ University Hospital Medical Center Bezanijska Kosa, Faculty of Medicine, University of Belgrade, Белград; ${ }^{2}$ Clinic for Internal Medicine Intermedica, Нис; ${ }^{3}$ Institute for Child and Mother Care "Vukan Cupic", Dept. of Cardiology, Faculty of Medicine University of Belgrade, Белград; ${ }^{4}$ Clinic for Cardiology, Faculty of Medicine, University of Nis, Hnc; ${ }^{5}$ Institute for Medical Statistics, Faculty of Medicine, University of Belgrade, Белград; ${ }^{6}$ Institute for Physiology, Faculty of Medicine, University of Belgrade, Белград; ${ }^{7}$ Clinical Center of Serbia, Faculty of Medicine, University of Belgrade, Белград, Сербия. 


\section{Introduction}

ECG and echocardiographic changes in athletes are common and usually reflect structural and electrical remodeling of the heart as an adaptation to regular physical training and hemodynamic changes that alter the loading conditions of the heart, causing the athlete's heart syndrome. [1] However, the level and duration of training or competition, aerobic capacity and type of sports activity play an important role in the extent of physiological changes of athlete's heart syndrome.Several studies have shown that corrected QT interval (QTc) interval in rest, although still in physiological limits, is prolonged in adult professional athletes compared to sedentary age-matched controls, [2] The main cause of this prolongation was physiological left ventricular hypertrophy, common in athletes. Left ventricular hypertrophy is related to the level and duration of physical training and is less common in adolescent athletes, where the left ventricular dilatation is frequently seen. [3] However, some new studies proved that left ventricular dilatation is the main pattern of the early left ventricle remodeling in the beginning of the active sports career in the youngest athletes. $[4,5]$ The 2005 Study Group of Sport Cardiology of the European Society of Cardiology recommend that a 12-lead ECG (in addition to a history and physical examination) should be a part of the pre-participation screening of young competitive athletes for prevention of sudden death. That document included criteria for a positive 12-lead ECG and specified values of the heart rate corrected QT interval (QTc more then $440 \mathrm{~ms}$ in males and $460 \mathrm{~ms}$ in females) [6].

In the following study the hypothesis was tested: there might be a difference in QTc interval duration between two compared groups in early adolescent period: elite football players and age-matched sedentary controls, and that QTc interval, measured from a single lead, would correlate with echocardiographic parameters of professional football players. The second aim of this study is to address the relative lack of data in the literature regarding normal values of QTc in adolescent population of football players and to define normal ranges of QTc for the athletes in early adolescent period.

\section{Study design}

\section{Material and Methods}

A group of 94 Caucasian elite male footballers aged $12,85(0,84)$, all members of the National Football Premier League clubs age range 12-14 years. The control group consisted of 47 healthy male age-matched sedentary controls, who were not exercising regularly (sport-training for not more than 2 hours a week). None of the participants had any symptoms attributable to cardiovascular disease. No subject was taking any form of prescribed drug treatment. Physical examination was without any pathological findings in all participants. They all were normotensive and nonsmokers. All athletes had been regularly engaged in active training for at least three years and were in their active training season. They had, on average, 9 hours of weekly training which included: 5 hours specific football training, 2 hours anaerobic dynamic training, 1 hour strength training and 1 hour aerobic endurance activities. The sample size was calculated to have a power more then $80 \%$ to detect a difference at $p<0,05$. [7]

Echocardiographic evaluation was performed by the same experienced cardiologist who was blind to the subject's training group, on every occasion using Acuson Sequoia computed sonography platform with a probe frequency $3.5 \mathrm{MHz}$ vector array format transducer following the recommendations of the American Society of Echocardiography. [7] The images were obtained in the parasternal long and short axis, in left lateral position and also in the four chamber view and then analyzed off-line. Both M-Mode and cross sectional studies were performed. The measurements of the left atrium (LA), aortic root (AO), left ventricular end diastolic dimension (LVED), left ventricle end systolic dimension (LVES), left ventricle posterior wall diastolic dimension (PWd), interventricular septal diastolic dimension (IVSd), were done in the parasternal long axis view, by the average of 3 consecutive cardiac cycles with concomitant ECG and the average was calculated. Left ventricular ejection fraction (EF) was calculated by Simpson's rule. Left ventricular mass (LV mass) was calculated using the method described by Devereux et al. [7] $13,6 \mathrm{~g}$

$\mathrm{LVM}=1,04 \times[(\mathrm{LVED}+\mathrm{PWd}+\mathrm{IVSd}) 3-$ LVED3 $]-$

Left ventricular mass index (LVMI) was calculated by standard dividing LV mass by BSA. [7]

All heart valves were assessed by standard technique in order to exclude significant valvular and subvalvular obstruction and regurgitation. Valve regurgitation severity was evaluated according to the recommendations of the American Society of Echocardiography (ASE) Guidelines [7].

As LVM is known to vary with body size and composition, normalization of LV dimensions according to body size is very important in comparisons between different subjects groups. In children and adolescents increased cardiac size is directly proportional to the increases of body height, so these adjustments according to body size were done for comparison of cardiac dimensions: LV mass findings were adjusted to BSA ${ }^{1.5}$ and LVM was additionally adjusted to height ${ }^{2.7}[7]$.

Standard 12-lead electrocardiogram (EGC) was recorded using a Nihon Cohden recorder with a paper speed of $25 \mathrm{~mm} / \mathrm{s}$ and amplification of $0.1 \mathrm{mV} / \mathrm{mm}$. The QT interval was measured in all leads from the onset of QRS complex to the end of $\mathrm{T}$ wave, defined as the intersection of isoelectric line and the tangent of the maximal downward limb of the T wave. [15] The U-wave was excluded during the measurement of the QT interval, except when the T wave was biphasic or in the presence of $\mathrm{T}-\mathrm{U}$ complexes 
where the identification of the termination of the $T$ wave was difficult. In such cases, the U-wave was included if it exceeded $50 \%$ of the T-wave amplitude. In the presence of biphasic $\mathrm{T}$ waves, we have also assessed the QT interval in other leads that did not exhibit biphasic $\mathrm{T}$ waves. The lead with the longest QT interval was used to obtain an average QT over three to five consecutive beats. The QTc values were derived using Bazett's formula, which has been most widely used in all large studies evaluating patients with LQTS [16]. The Bazett correction is commonly used in QTc interval investigations and involves dividing the uncorrected QT (in seconds) by the square root of the RR interval (in seconds). The limitations of this method are overcorrection at faster heart rates (lower RR intervals) and under-correction at slower heart rates (higher RR intervals).

All ECGs were analyzed independently by two independent cardiologists with a clinical and academic interest in LQTS, blinded to all clinical details of the subjects, using a millimeter ruler and calipers. According to internationally accepted guidelines, males with a QTc value of $440 \mathrm{~ms}$ and females with a QTc value of $460 \mathrm{~ms}$ were considered to have an abnormally prolonged QTc interval. [8]

\section{Statistical analysis}

Continuous data are expressed as mean (SD), with 5th and 95th percentile ranges to facilitate comparison with the data belonging to the controls. Statistical analysis was carried out using unpaired t-tests between groups. Statistical significance is stated as $p<0.05$.

\section{Results}

Selected physical characteristics of the footballers and the controls are shown in Table 1.

The footballers had similar height as the control group, but significantly smaller weight and BSA. Heart rate was
The characteristics of the 94 footballers and 47 agematched non-athletes (the mean and SD)

\begin{tabular}{|l|l|l|}
\hline & Footballers & Non-athletes \\
\hline Age $($ years $)$ & $12,85(0,84)$ & $12,85(0,86)$ \\
\hline Height $(\mathrm{cm})$ & $159,36(10,65)$ & $162,71(13,09)$ \\
\hline Weight $(\mathrm{kg})$ & $48,27(10,62)^{*}$ & $58,28(13,07)$ \\
\hline BSA $\left(\mathrm{m}^{2}\right)$ & $1,45(0,20)^{*}$ & $1,61(0,24)$ \\
\hline BMI $\left(\mathrm{kg} / \mathrm{M}^{2}\right)$ & $18,75(1,92)^{*}$ & $21,59(1,86)$ \\
\hline HR $(\mathrm{bpm})$ & $83,49(14,50)^{*}$ & $88,8(5,19)$ \\
\hline Systolic blood pressure $(\mathrm{mmHg})$ & $109,95(8,08)$ & $108,19(6,71)$ \\
\hline Diastolic blood pressure $(\mathrm{mmHg})$ & $65,74(7,89)^{*}$ & $60,75(5,80)$ \\
\hline
\end{tabular}

* $-p<0,001$.

Abbreviations: BSA - body surface area, HR - heart rate.

significantly lower in athletes then in control subjects. Values of systolic blood pressure were similar in both groups, but diastolic blood pressure was higher in athletes, nevertheless normal.

Table 2 shows the mean, SD, and 5th to 95th percentile ranges of the echocardiographic measurements and QTc values of the footballers as well as of the controls.

There was no difference in LV wall thickness and LV mass in these two compared groups. LVMI was significantly bigger in adolescent footballers, as well as specific indexes of left ventricle in athletes, like LVM/BSA ${ }^{1.5}(p<0,001)$ and $L V M / h^{2.7}(p<0,0001)$. Left atrial chamber size $(p<0,001)$, aortic root diameter $(p<0,001), L V$ end diastolic dimension $(p<0,05)$ and $L V$ end systolic dimension $(p<0,001)$ were also significantly increased in the footballers compared to the age matched control group data. There also was no significant difference in mean left ventricular ejection fraction (EF) and shortening fraction (SF) in the compared groups. The footballers had mean (SD) ejection fraction $68,23(4,36) \%$ and the subjects in

Table 2

Comparison of the resting echocardiographic findings in 94 footballers and 47 age-matched non-athletes and correlation between QTc interval duration and echocardiographic parameters in adolescent young footballers (the mean and SD)

\begin{tabular}{|c|c|c|c|}
\hline & Footballers & Non-athletes & QTc correlation \\
\hline Ao $\left(\mathrm{mm}\right.$ per $\left.\mathrm{BSA}^{0,5}\right)$ & $21,87(2,08)$ * & $15,65(1,36)$ & $0,478 \S$ \\
\hline $\mathrm{LA}\left(\mathrm{mm}\right.$ per $\left.\mathrm{BSA}^{0,5}\right)$ & $23,18(2,07)$ * & $20,15(2,87)$ & $0,221 \S$ \\
\hline LVED (mm per BSA ${ }^{0,5}$ ) & $38,72(2,53)$ * & $35,68(2,54)$ & $0,351 \S$ \\
\hline LVES (mm per $\mathrm{BSA}^{0,5}$ ) & $25,83(2,58)$ * & $20,75(2,30)$ & $0,374 \S$ \\
\hline IVSd (mm per $\left.\mathrm{BSA}^{0,5}\right)$ & $7,08(0,70)$ & $6,53(0,81)$ & 0,089 \\
\hline $\mathrm{PWd}\left(\mathrm{mm}\right.$ per $\left.\mathrm{BSA}^{0,5}\right)$ & $6,82(0,73)$ & $6,46(0,80)$ & $-0,045$ \\
\hline $\operatorname{LVM}(g)$ & $160,14(33,14)$ & $149,59(34,01)$ & 0,096 \\
\hline LVMI (g per BSA) & $109,79(15,04)$ * & $92,84(18,29)$ & $0,235 \S$ \\
\hline $\operatorname{LVM} \mathrm{BSA}^{1,5}\left(\mathrm{~g}\right.$ per $\left.\mathrm{BSA}^{1,5}\right)$ & $91,55(13,86)$ * & $73,73(16,54)$ & $0,339 \S$ \\
\hline $\mathrm{LVM} / \mathrm{h}^{2,7}\left(\mathrm{~g}\right.$ per $\left.\mathrm{h}^{2,7}\right)$ & $45,78(9,47)^{*}$ & $40,65(9,29)$ & $0,298 \S$ \\
\hline QTc (msec) & $419,89(13,27)$ * & $399,78(13,07)$ & / \\
\hline
\end{tabular}

* $-p<0,01$ compared to controls, $\S-p<0,01$ correlation of echocardiographic parameters and QTc interval duration.

Abbreviations: Ao - aortic root diameter, LA - left atrium, LVED - left ventricular end-diastolic dimension, LVES - left ventricular end-systolic dimension, IVSd ventricular septal thickness (diastole), PWd - ventricular posterior wall thickness (diastole), LVM — left ventricular mass, LVMI — left ventricle mass index, $\mathrm{h}$ - height. 
Table 3

The ECG characteristics of the 94 footballers and 47 agematched non-athletes (the mean and SD)

\begin{tabular}{|l|l|l|}
\hline & Footballers & Non-athletes \\
\hline QRS d (msec) & $82,44(1,30)^{*}$ & $76,01(0,71)$ \\
\hline QRS v (mV) & $159,36(10,65)^{*}$ & $162,71(13,09)$ \\
\hline PR interval (msec) & $174,02(3,57)^{*}$ & $162,84(1,56)$ \\
\hline P v (mV) & $1,96(0,16)^{*}$ & $1,34(0,46)$ \\
\hline
\end{tabular}

$*-p<0,001$

Abbreviations: QRS d - QRS duration, QRS v - QRS voltage, PR interval duration of $\mathrm{PR}$ interval, $\mathrm{P}$ wave $\mathrm{v}-\mathrm{P}$ wave voltage.

the control group $68,49(4,72) \%$. The mean (SD) fraction of shortening was $38,01(3,84) \%$ in footballers and 38,36 $(3,95) \%$ in the control group. No regional wall motion abnormalities of either the right or the left ventricle were seen. All study participants had normal LV diastolic function and $\mathrm{E} / \mathrm{a}$ ratio $>1$.

All participants (aged 12-14) had normal values of QTc interval. Mean QTc interval in athletes in rest was significantly longer $419,89 \pm 13,07 \mathrm{msec}$, compared to mean QTc in the control sedentary group - 399,78 $\pm 13,27$ msec $(p<0.001)$. The mean and SD of the QTc values in footballers as well as in non-athletes are shown in Table 2, together with correlation of these parameters to echocardiographic measurements.

In Table 2, the mean and SD of the QTc values in footballers as well as in non-athletes together with correlation of these parameters to echocardiographic measurements.

QTc interval duration in athletes had not very strong, but indeed positive correlation to left atrium dilatation, LV dilatation, LVMI, and most important to LVM / BSA ${ }^{1.5}$ and $\mathrm{LVM} / \mathrm{h}{ }^{2.7}$ indexes. There was no correlation between QTc interval duration and LV wall thickness.

In Table 3 ECG characteristics of footballers and nonathletes were compared.

\section{Discussion}

The study is unique regarding age of the investigated population widely and the first of the kind in Serbia. The data indicate normal values of QTc interval in all participants; however, QTc intervals in athletes were highly significantly longer. Positive correlations between QTc interval duration and echocardiographic dimensions of the left heart's cavities (ventricle and atrial) and aortic root were proven, suggesting the concomitant morphological, functional and electrical early heart remodeling even in the preadolescent period. It was not surprising that the resting heart rates of the athletes were faster than the typically reported heart rate in the previous studies, sine this was the unique age group of athletes.

There was no difference in LV wall thickness and LV mass in these two compared groups. However, we could not exactly say there was no LV hypertrophy, since LVMI was significantly bigger in adolescent footballers, as well as specific indexes of left ventricle in athletes, like LVM/ $\mathrm{BSA}^{1.5}(\mathrm{p}<0,001)$ and $\mathrm{LVM} / \mathrm{h}^{2.7}(\mathrm{p}<0,0001)$. It is very important to observe that, although there are no increased dimensions of the LV wall, QTc prolongation in preadolescent footballers is very closely linked to the LV hypertrophy, characterized by increased LVMI and specific $\mathrm{LV}$ indexes $\left(\mathrm{LVM} / \mathrm{BSA}^{1.5}\right.$ and $\left.\mathrm{LVM} / \mathrm{h}^{2.7}\right)$.

As it is well known, the long QT syndrome (LQTS) is a genetic disorder characterized by prolongation of the QT interval in the electrocardiogram (ECG) and a propensity to torsades de pointes ventricular tachycardia frequently leading to syncope, cardiac arrest, or sudden death usually in young otherwise healthy individuals. [9] The first description of QT interval in athletes during rest and exercise was given by Ring GC et al. in 1972. [9] In athlete population the QTc interval prolongation was demonstrated through a huge number of studies; in all of them there were also left ventricular hypertrophy with increased left ventricle wall thickness, suspected to be the cause of the prolongation. But increased left ventricle wall thickness is not common in preadolescent period and consequently QTc prolongation is less likely to be expected.

The relationship between occurrence of arrhythmias and QT prolongation in athletes was described later [10], some studies have even linked QT interval prolongation in physical exercise to some undiagnosed cardiac disease [11]. The QT interval prolongation was proved even in animals with high physical exercise - highly trained dogs [11].

The prevalence of QT interval prolongation in asymptomatic elite athletes was recently reported as $0,4 \%$, or 1 in 286 patients. Palatini et al. reported in a group of 30 young athletes the QTc interval prolongation, but no correlations between QTc prolongation and the degree of severity of ventricular ectopic beats, heart rate or echocardiographic dimensional and functional findings were found [12]. Factors which play a role in these QT interval changes are a lower intrinsic heart rate, an increased parasympathetic or vagal tone, a decrease in sympathetic tone, structural cardiac adaptations, and non-homogeneous depolarization of the ventricles. Alterations are mostly seen in athletes engaged in high intensity dynamic endurance sports. It is important to recognize that several of the ECG changes that can accompany athletic conditioning resemble pathological ECG features and may mimic structural heart disease. QTc interval prolongation was described by Stolt et al. in female athletes, much older than our group [13]. In the same study, QTc prolongation also correlated with LV and RV mass and increased LV wall thickness. According to Sharma et al. highly significantly prolonged QTc interval should be linked to the frequently registered ECG signs of left ventricle hypertrophy [14].

However, still our data indicate no correlation between QTc interval duration and LV wall thickness, analysis of 
specific LV mass indexes revealed significant differences within, suggesting that correlation between these indexes and QTc prolongation could be the explanation for the QTc prolongation. Furthermore, QTc prolongation could be the early ECG marker of physiological LV remodeling in young preadolescent footballers, without any other standard ECG and echocardiographic signs of early LV hypertrophy. This fact could be explained by a different pattern of left ventricle remodeling in preadolescent period, where LV wall thickness increase cannot usually be seen and the predominant characteristic is left ventricle dilatation. In our opinion QTc prolongation in athletes is related to the early cardiac remodeling and can be seen even after a short period of training; nevertheless recommended normal values of QTc interval in young preadolescent footballers should be expected [15].

\section{Limitations}

The study is limited to Serbian Caucasian preadolescent footballers and differences with other races can occur. However, the number of investigated elite footballers in the preadolescent age is limited by the small number of the elite footballers of that age - all preadolescent elite footballers were enrolled in our study. Although further studies are necessary, we expect athletes with different

\section{References}

1. Baggish AL, Wood MJ. Athlete's heart and cardiovascular care of the athlete: scientific and clinical update. Circulation 2011;123:2723-35.

2. Walker $\mathrm{J}$, Calkins $\mathrm{H}$, Nazarian $\mathrm{S}$. Evaluation of cardiac arrhythmia among athletes. Am J Med 2010;123:1075-81.

3. Westrol MS, Kapitanyan R, Marques-Baptista A, et al. Causes of sudden cardiac arrest in young athletes. Postgrad Med 2010;122:144-57.

4. Corrado D, Pelliccia A, Heidbuchel H, et al. Section of Sports Cardiology, European Association of Cardiovascular Prevention and Rehabilitation. Recommendations for interpretation of 12-lead electrocardiogram in the athlete. Section of Sports Cardiology, European Association of Cardiovascular Prevention and Rehabilitation. Eur Heart J 2010; 31: 243-59.

5. Basavarajaiah S, Wilson M, Naghavi R, et al. Physiological upper limits of left ventricular dimensions in highly trained junior tennis players. Br J Sports Med 2007;41:784-8.

6. Zdravkovic M, Perunicic J, Krotin M, et al. Echocardiographic study of early left ventricular remodeling in highly trained preadolescent footballers. J Sci Med Sport 2010;13:602-6.

7. Naylor LH, George K, O'Driscoll G, et al.The athlete's heart: a contemporary appraisal of the 'Morganroth hypothesis'. Sports Med 2008;38:69-90.

8. Rautaharju PM, Surawicz B, Gettes LS, et al; American Heart Association Electrocardiography and Arrhythmias Committee, Council on Clinical Cardiology; American College of Cardiology Foundation; Heart Rhythm Society American Heart Association Electrocardiography and Arrhythmias Committee, Council on Clinical Cardiology; American College of Cardiology Foundation; Heart Rhythm Society. sports to have similar findings. Both the development and degree of LVH and QTc prolongation are multifactorial, thus hypertrophy modulated by other causes (i.e.genotype) could not be excluded. Although Bazett's correction that was used may overcorrect more at a heart rate of 89 than at 83 , in our opinion this will not likely make a difference in the results of the study.

\section{Conclusion}

In summary, the study showed that there is a prolongation of QTc interval in highly trained preadolescent footballers compared to the QTc interval in teenagers with sedentary life style, correlating with specific LV mass indexes. However, this prolongation is still within recommended values. QTc prolongation could be the early ECG marker of physiological LV remodeling in young preadolescent footballers, without any other standard ECG and echocardiographic signs of early LV hypertrophy.

\section{Acknowledgments}

The results of the paper are part of $\mathrm{PhD}$ thesis of Marija Zdravkovic. There were no grants, no external financial or technical support or other assistance during the evaluation of the paper. None of the authors declare conflict of interests.

AHA/ACCF/HRS recommendations for the standardization and interpretation of the electrocardiogram: part IV: the ST segment, T and U waves, and the QT interval: a scientific statement from the American Heart Association Electrocardiography and Arrhythmias Committee, Council on Clinical Cardiology; the American College of Cardiology Foundation; and the Heart Rhythm Society. Endorsed by the International Society for Computerized Electrocardiology. J Am Coll Cardiol 2009;53:982-91.

9. Zareba W, Cygankiewicz I. Long QT syndrome and short QT syndrome. Prog Cardiovasc Dis 2008;51:264-78.

10. Walker J, Calkins $\mathrm{H}$, Nazarian S. Evaluation of cardiac arrhythmia among athletes. Am J Med 2010;123:1075-81.

11. Basavarajaiah S, Wilson M, Whyte G, et al. Prevalence of hypertrophic cardiomyopathy in highly trained athletes: relevance to pre-participation screening. J Am Coll Cardiol 2008;51:1033-39.

12. La Gerche A, Macisaac Al, Prior DL. Should pre-participation cardiovascular screening for competitive athletes be introduced in Australia? A timely debate in a sport-loving nation. Heart Lung Circ 2011;20: 629-33.

13. Basavarajaiah $\mathrm{S}$, Wilson $\mathrm{M}$, Whyte $\mathrm{G}$, et al. Prevalence and significance of an isolated long QT interval in elite athletes. Eur Heart J 2007;28: 2944-9.

14. Drezner JA, Fischbach P, Froelicher V, et al. Normal electrocardiographic ndings: recognising physiological adaptations in athletes. Br J Sports Med 2013;47:125-36.

15. Chandra N, Papadakis M, Sharma S. Cardiac adaptation in athletes of black ethnicity: differentiating pathology from physiology. Heart 2012;98:1194-200. 